\title{
Da ociosidade ao ócio da cidade: perspectivas para a Educação Física no meio urbano
}

From idleness to city leisure: perspectives for Physical Education in the urban environment

De la ociosidad al ocio de la ciudad: perspectivas para la educación física en el medio urbano

\author{
Ricardo Alves Mendes ${ }^{\mathrm{I}}$, Giuliano Gomes de Assis Pimentel ${ }^{\mathrm{II}}$
}

\begin{abstract}
Resumo
A obra "Ócio e Cidade" contém pesquisas sobre a transformação dos espaços urbanos a partir do ócio. Cada capítulo agrega mais de um estudo sobre o ócio em relação aos eixos envelhecimento, cultura popular, juventude, educação e saúde. O ócio é compreendido como uma experiência humana integral, direito fundamental e de desenvolvimento pessoal, social e comunitário. Tais reflexões permitem ao leitor tirar o ócio da ociosidade e conhecer a utopia do ócio da cidade. Recomenda-se o livro a pesquisadores do lazer, do "ócio humanista" e para professores de Educação Física envolvidos com políticas culturais nos centros urbanos.
\end{abstract}

Palavras-chave: Atividades de Lazer; Centros de Convivência e Lazer; Planejamento de Cidades. Mudança social

\begin{abstract}
The book Ócio e Cidade (Leisure and the City) contains research on transformation of urban spaces from Leisure. Each chapter adds more than one study on leisure in relation to aging, popular culture, youth, education and health axes. Leisure is understood as an integral human experience, a fundamental human right and a personal, social and community development factor. Such reflections allow the reader to take leisure out of idleness and learn the utopia of the city leisure. The book is recommended to researchers in the area of leisure and "humanistic leisure" and to Physical Education teachers involved with cultural policies in urban centers.
\end{abstract}

Key words: Leisure Activities; Centers of Connivence and Leisure; City Planning. Social Change

\footnotetext{
I Universidade Estadual de Maringá - UEM - Endereço: Av. Colombo, 5790 - Zona 7, Maringá - PR, 87020-900 - e-mail: ricardoalvesmendes0303@gmail.com

II Universidade Estadual de Maringá - UEM - e-mail: ggapimentel@uem.br
} 


\section{Resumen}

La obra "Ócio e Cidade" (Ocio y Ciudad) contiene investigaciones sobre la transformación de los espacios urbanos a partir del ocio. Cada capítulo agrega más de un estudio sobre el ocio en relación a los ejes envejecimiento, cultura popular, juventud, educación y salud. El ocio se entiende como una experiencia humana integral, un derecho humano fundamental y un factor de desarrollo personal, social y comunitario. Tales reflexiones permiten al lector sacar el ocio de la ociosidad y conocer la utopía del ocio de la ciudad. El libro es recomendado a investigadores del área del ocio y del "ocio humanista" y también para profesores de Educación Física involucrados con políticas culturales en los centros urbanos.

Palabras clave: Actividades de Ocio; Centros de Ocio y Convivencia; Planificación de Ciudades; Cambio Social

Nesta resenha, realizamos a exegese do livro "Ócio e cidade: o papel do ócio na transformação das cidades", a partir da premissa de que, com a Modernidade, o lazer é produzido como dispositivo de racionalização do tempo livre, compreendido em um amplo processo de domesticação dos impulsos lúdicos. Por sua vez, do ponto de vista filosófico, o ócio começa a perder espaço, seja por representar privilégio de classe em relação ao desenvolvimento pessoal, seja por não gerar lucro. Essa transição foi refletida no campo acadêmico, que tomou para si a categoria lazer como objeto privilegiado (PIMENTEL, 2018).

Outra possibilidade de entender ócio e lazer são os sinônimos, dadas as variações linguísticas, ou pela localização de divertimentos na Humanidade desde outras épocas. Isso mostra que há um debate aberto da terminologia à teleologia em relação ao ócio. Quem se habilitará a produzir novas sínteses a respeito dessa demanda?

Dessa forma, chama atenção encontrar, na Educação Física, um coletivo acadêmico que busca originalidade intelectual por meio de estudos sobre o ócio. A obra "Ócio e Cidade" foi organizada por Cláudio Augusto Silva Gutierrez e Fernando Edi Chaves, ambos da Universidade do Vale do Rio dos Sinos (UNISINOS). Eles reuniram produções no âmbito da América Latina, Espanha e Portugal. A realização do trabalho foi possível graças à Rede OTIUM, uma Associação Ibero-Americana de Estudos do Ócio, composta atualmente por pesquisadores de dezenove universidades, de nove países.

Cada um dos cinco capítulos agrega mais de um estudo sobre o ócio, como uma experiência humana valiosa. Os recortes perpassam a perspectiva do envelhecimento, da cultura popular, da juventude, da educação e da saúde. Em síntese, referem-se a pesquisas sobre o ócio e a transformação dos espaços urbanos das cidades investigadas.

Cabe ressaltar que, na língua espanhola, não existe a palavra "lazer", e sim a palavra "ócio", mas os pesquisadores da Associação Ibero-Americana de Estudos do Ócio (Rede Otium) resistem à tradução direta de ócio por lazer. Para eles, o ócio é compreendido como "uma experiência humana integral, direito 
humano fundamental e fator de desenvolvimento pessoal, social e comunitário”. Busca-se reforçar a dimensão de experiência humana e integral, que articula a subjetividade, o direito social em diferentes dimensões. Muitas vezes, o ócio fala de campos correlatos ao lazer, como "tempo livre, cultura, turismo, esporte e recreação". No entanto, neste livro, os autores, em sua maior parte, assumem o ócio como uma provocação, um questionamento, uma abertura a novas possibilidades de compreensão da experiência humana nesses campos.

A esse respeito, destacamos a lavra de Manuel Cuenca introduzindo o livro. Por ser a principal referência nos estudos do ócio e nas suas categorias (valioso, humanista, autotélico e experencial), Cuenca está autorizado a fazer um Estado da Arte sobre ócio e urbanidade. Tomando Bilbao, como exemplo, assinala dois relevantes momentos sobre a incidência do ócio na transformação das cidades. $\mathrm{O}$ primeiro momento foi o período em que o ócio constituiu uma Estratégia do Estado de Bem-Estar Social e respondeu pela construção de grande parte das instalações esportivas. O segundo, foi o momento em que o ócio se tornou o eixo das políticas de regeneração física e econômica de muitas cidades do mundo ocidental. A segunda fase, todavia, refere-se mais à cidade como destino turístico do que ao ócio voltado para os cidadãos.

Cuenca defende que o objetivo de transformar as cidades não pode ter rentabilidade imediata, mas sim um projeto a longo prazo, integral e compartilhado, que busque o bem-estar dos cidadãos. Isso pode ser feito através da programação e esforços unidos que garantam a sustentabilidade de forma mais definitiva. Também é crucial desenvolver técnicas para avaliar impactos e legados culturais e planos estratégicos que orientem a transformação das cidades, a partir de abordagens de um ócio humanista e experiencial.

O primeiro capítulo "Ócio e Envelhecimento" possui dois textos. O primeiro, intitulado "Jogando, convivendo, e envelhecendo: uma experiência do Grupo de Câmbio da Praça”, de Bianca Simon, Silvana Bianchi e Susana Wolff, fala sobre um projeto ligado ao Programa Social Pró-Maior, da Universidade do Vale dos Sinos, da cidade de São Leopoldo/RS. As autoras cruzam uma prática, jogo de câmbio praticado por idosos, com um contexto, jogar regularmente em uma praça. Para tanto, apresentam o contexto da ação para chegar à reflexão sobre os significados e sentimentos compartilhados na ação/ intervenção.

O segundo texto, intitulado "Processo de envelhecimento ativo e saudável: caminhamos pela vida... por tua saúde, bem-estar e felicidade", de Angel Cruz e Yivy Parra, trata da questão dos espaços saudáveis, lúdicos, recreativos e culturais como meios para o desfrute do tempo. O contexto reporta-se à integração social da comunidade da Universidade Sulcolombiana, situada na cidade Neiva, Huila, com pessoas entre 40 a 87 anos residentes próximas à universidade. As discussões surgem a partir das 
dimensões de bem-estar para um bom desenvolvimento humano, conforme o ciclo vital e qualidade de vida.

No segundo capítulo, “Ócio e Cultura Popular”, são apresentados três estudos: dois realizados pela Universidade YMCA (MEX) e um realizado em Porto Alegre, pela Universidade UNISINOS (BRA). O primeiro, denominado "A cidade do México, sua transformação e suas práticas de ócio no porfiriato", de Elena Paz Morales, investigou a história do México, de 1877 e 1910, período da presidência de Porfirio Diáz, fazendo a leitura do ócio desse país no período de transição entre o tradicional e o moderno.

O segundo estudo, "Atividades complementares programadas por museus que incidiam em experiências de ócio humanista - Estudo de caso: museus na cidade do México", de Rocio Isabel Caballero Alvarado, investigou 72 museus no período de 2015 a 2016 e, a partir de atividades complementares programadas, desenhou um modelo de análise conforme dois eixos: 1) o ócio humanista e sua relação com a experiência humana e 2) um modelo para a educação do ócio a curto prazo.

E, por fim, em "A vadiação no ócio: a roda de capoeira no chafariz da Redenção", Anselmo da Silva Accurso descreveu a "vadiação" que acontece durante a roda de Capoeira Angola no chafariz do Parque da Redenção em Porto Alegre - RS. O autor infere que há relação entre a vadiação na capoeira e a experiência de ócio, atribuindo a isso sensações de pertencimento e o aprendizado de valores como respeito, humildade e liberdade.

“Ócio e Juventudes" é o terceiro capítulo, composto por quatro estudos: dois oriundos de universidades brasileiras (UFPI e UNISINOS) e de duas europeias (Deusto, na Espanha, e Aveiro-UA, em Portugal). Neste caso, aborda-se o ócio e o lazer como uma experiência humana integral, direito humano fundamental e fator de desenvolvimento pessoal, social e comunitário em jovens. Os artigos, a partir dessas relações, abordam nichos, como universitários, adolescentes e crianças, escolares e consumidores de videoclipes. Para tanto, são apresentadas relações entre a forma de satisfação do lazer e suas necessidades existenciais, o direito ao esporte e lazer em território de alta vulnerabilidade, os hábitos desportivos e a natureza dos conteúdos mais consumidos em tempo de lazer e ócio e os tipos de relacionamentos amorosos.

Por sua vez, o capítulo 4, "Ócio e Educação", reuniu cinco trabalhos realizados por docentes e discentes (UFMG, UNISINOS, IFMT Campus São Vicente, Universidade Sulcolombiana e UFPI). A ênfase é dada ao ócio humanista e busca-se analisar multidisciplinarmente diferentes aspectos da educação. Para tanto, são apresentadas relações, na comparação de cursos técnicos e de graduação, em lazer, experiências sociais de aprendizagens esportivas, ensino de filosofia e ócio, proposta de lazer para o 
binômio lazer-família e políticas públicas de lazer. Os artigos, a partir desses enfoques, abordam populações como estudantes e acadêmicos, escolares, aposentados e suas famílias e a população em geral.

“Ócio e Saúde”, capítulo 5, é estrutrado a partir de três estudos realizados no Rio Grande do Sul (Montenegro, Porto Alegre, Sapucaia do Sul). É evidenciado o ócio como valor que enriquece a análise multidisciplinar da saúde. Para tanto, são apresentadas relações entre composição corporal e autoimagem, experiências de ócio e resiliência, música e saúde mental. Os artigos, a partir dessas relações, abordam nichos como mulheres, trabalhadores, usuários de saúde mental e pessoas da comunidade em geral (frequentadores da praça).

Depreende-se, assim, que essa obra vem somar-se à singularidade de produções sobre lazer e espaço urbano. Particularmente, na Educação Física brasileira, como referencial teórico, quase solitário, há a produção de Simone Rechia (2015), junto com o Grupo de Estudos e Pesquisas em Lazer, Espaço e Cidade (GEPLEC). A referida autora postula o "lazer urbano" como uma possibilidade de a cultura se manifestar por meio de uma apropriação crítica e criativa dos espaços públicos.

O livro, conforme identificado, vem somar-se a essa linha de reflexões sobre como tornar a cidade um lugar para se viver com mais qualidade. Para tanto, os capítulos elegeram subtemas: envelhecimento, cultura, juventude, educação e saúde. Esses eixos são coerentes com as linhas de investigação de Cuenca na realidade espanhola. Todavia, esse pode ser um aspecto limitante da originalidade do material, uma vez que discussões mais localizadas na urbanização brasileira (desigualdade, poluição, conurbação, entre outras) foram secundarizadas.

Outro aspecto de destaque na obra é a possibilidade de dialogar com uma vertente diferente, a do ócio. Ressaltamos que este livro acolheu abordagens de diferentes áreas de conhecimento. Outra marca de sua pluralidade é a participação de autores e autoras do Brasil, Uruguai, Colômbia, México, Portugal e Espanha. Essa riqueza em diversidade, todavia, exigirá uma leitura criteriosa no sentido de nem sempre haver uma coerência teórica e terminológica sobre ócio.

A esse respeito, entre os dezoito textos, oito deles falam sobre ócio em uma perspectiva mais ampla, ou seja, ócio como ideal, experiência humana integral, direito fundamental e fator de desenvolvimento pessoal, social e comunitário. Outros oito textos operam com categorias do lazer (esporte e lazer, políticas públicas de lazer, direito ao lazer). Um dos textos, em espanhol (não há vocábulo correspondente a lazer nessa língua), conforme mencionado no quinto parágrafo da resenha. E o último opera as duas categorias, trazendo distinções conforme a interpretação do pesquisador: potencial humano ou coletivo, de autoafirmação e identificação, de uma experiência processual em nossas vidas, 
mostrando uma vivência completa (para ócio) ou, ainda, passatempo, uma recreação compensatória, com significado intrínseco (para lazer).

Nossa entrevista aos organizadores corroborou a interpretação do ócio como "algo mais amplo" que quer provocar um questionamento, uma abertura a novas possibilidades de compreender a experiência humana. Ou seja, busca-se reforçar a dimensão de experiência humana e de experiência integral, que articula a subjetividade, o direito social e o desenvolvimento pessoal e comunitário em diferentes dimensões.

Em sociedades capitalistas, a categoria lazer é mais facilmente assimilada aos interesses do mercado. Lazer dá negócio. Mas negócio é a negação do ócio (nec otium), então o termo ócio oferece mais resistência à sua redução a mercadoria. Não é um antídoto, porque o mercado começa a querer vender experiências, o gozo, inclusive a categoria "ócio". Mas, como ainda é estranho falarmos em ócio, desse "estranhamento" vem sua força. Embora o entendimento corrente de ócio na América Latina, e especialmente no Brasil, não acompanhe essa teleologia, é uma interpretação possível e que precisa ser cotejada à luz dos debates geopolíticos no campo, como propõe Gomes (2011).

Os organizadores defendem a teoria do ócio na Educação Física, porque o exercício das culturas do movimento deve colocar-se para além do ensinar uma cultura esportiva, disciplinar o tempo livre ou adestrar o corpo e o espírito. Como experiência de um ócio valioso, o exercício das culturas do movimento deve comprometer-se com o desenvolvimento integral da pessoa, com a defesa de direitos e a promoção da justiça social, e com um projeto de valores humanos. Em suma, a uma prática renovada de Educação Física, é possível agregar um ideal de ócio revisado para o tempo presente.

Por fim, sugerimos a leitura a pesquisadores da área do lazer e do "ócio humanista", bem como, para professores de Educação Física envolvidos com Recreação, Esporte e Lazer, principalmente com políticas nos centros urbanos. A discussão atualizada sobre ócio reserva potencial de originalidade para estudos e pode ser uma ferramenta teórica para a prática profissional mais crítica. Não obstante os limites apontados na obra, fomenta tirar o ócio da ociosidade para a utopia do ócio da cidade, trazendo perspectivas avançadas para a educação física na urbanidade.

\section{Referências}

GOMES, Christianne Luce. Estudos do Lazer e geopolítica do conhecimento. Licere, Belo Horizonte, v. 14, n. 3, 2011.

GUTIERREZ, Cláudio. A. S.; CHAVES, Fernando E. (Orgs.). Ócio e cidade: o papel do ócio na transformação das cidades. São Leopoldo: Unisinos, 2018. 
PIMENTEL, Giuliano G. A. Grupo de estudos do lazer (GEL). In: UVINHA, Ricardo. R. (Org.). Lazer no Brasil: grupos de pesquisa e associações temáticas. São Paulo: Edições temáticas, p. 224-239, 2018.

RECHIA, Simone. Cidadania e direito ao lazer nas cidades brasileiras: da fábula à realidade. In: GOMES, Christianne L.; ISAYAMA, Hélder F. (Orgs.). O direito social ao lazer no Brasil. Campinas: Autores Associados, 2015.

\section{Como citar este artigo}

MENDES, R. A.; PIMENTEL, G. G. A. Da ociosidade ao ócio da cidade: perspectivas para a Educação Física no meio urbano. Revista Kinesis, Santa Maria, v. 39, p. 01-07, 2021.

* O presente trabalho não contou com apoio financeiro de nenhuma natureza para sua realização 